\title{
The Differences Effects of Training Method and Nutritional Status on Basic Technical Skills of Football Club Players in Mandailing Natal
}

\author{
Baik Wijaya*, Umar, Arsil \\ Faculty of Sports Science \\ Universitas Negeri Padang \\ baikwijaya02@gmail.com
}

\begin{abstract}
The purpose of this research is to determine the differential effect of training method and nutritional status on the necessary technical skills of SSB Madina athletes in Mandailing Natal Regency. The type of this research was quantitative with using experimental factorial design. The sample in this research amounted to 24 people. The instrument used in this study was a test of the necessary technical skills of football. The result of the data analysis showed that: (1) Elementary training method was more effective than the group modification training method in influencing the necessary technical skills of SSB Madina football athletes, (2) The high nutritional status group was more effective than the low nutritional status in influencing the necessary technical skills of SSB Madina athletes, (3) There was an interaction between the training method and nutritional status on the necessary technical skills of SSB football athletes, (4) In high nutritional status, the primary training method was more effective than the training method on the necessary technical skills of SSB Madina football athletes, (5) In low nutritional status, the primary training method was more effective than the training method on the necessary technical skills of SSB Madina football athletes.
\end{abstract}

Keywords - Training method, nutritional status, the basic technique, football skills

\section{INTRODUCTION}

Every football team wants maximum performance, of course the athletes must have good basic skills (techniques) to play, good basic ball skills will be born through the mastery of mature basic techniques, this is a form of effect of the proper training process, intensive and systematic so that if all these components are going well, the expected achievement will be achieved.

Technique, or special sport technical skills, is a major component in the development of athletes in many sports, including football. "Various tests have been developed to evaluate ball control with body (trapping), head (heading) and foot (dribbling), passing (short and long), including shooting accuracy, throwing and kicking for distance, dexterity and kick "[1].

"Each age level of students emphasizes the explanation, demonstration, and practice of football technique skills. The acquisition of movement skills is very important in the context of sports and economics. Normally, being skilled requires years of practice directed at the goal" [2].

"from an early age athletes must master the technique of playing football, each technique that is taught must be followed by consistent and continuing training program so that the technique can be mastered and turned into a skills, "namely the ability to use game techniques that can be used in every condition and obstacles that exist in every game" [3].

Besides that, "also explained that the importance of four special skills during football match in determining positive results"[4]. Dribbling seems to be the single most important skill when compared to passing, first touch, and defense. However, because the passing will affect the first touch skills and vice versa, these two skills must be practiced together. The combination of passing and first touch has to be shared much of the training time. Special attention must be used to design skills that encourage better first touches while still encouraging performance at these four points.

The four points in this study are started from the easiest technique movement of kicking the ball for example, which starts from the ball in a still state, rolling then until the ball is in a state of hovering or bouncing for kicking the ball technique. Similarly, in the beginning of the football branch dribble techniques (dribbling) the ball (passing), the ball (heading), to the direction of kicking the ball (shooting) to all of these techniques in rudimentary training methods and training methods modified game.

So, for the achievement of good basic football technical skills, it depends on the factors that influence it, the researcher examines various concepts, theories, articles, and journals related to training methods in football and examines the factors that influence the good achievement of basic technical skills of footbal. For these factors there are only two factors that influence the achievement of good basic football technical skills, namely internal and external. These factors are such as training methods and nutritional status.

The success of a coach in creating athletes with having technique, it requires directed, structured and 
planned training method. Reminding that the test is designed to replicate "certain areas of sports performance are usually used to investigate the effect of interventions on nutritional status" [5].

The main objective in this study is to determine the differences effect of training method and nutritional status on the basic technical skills of SSB Madina athletes in Mandailing Natal. In order to have good football skills, it is necessary to give an intensive training. The form of training provides several training methods that can be used as a way to obtain positive results on the athlete's football skills.

\section{METHOD}

This research is descriptive. Method used in this research is quantitative. Quantitative research method is a research method that based on positive philosophy and used to observe in population or certain sample. Collecting data use research instrument, "data analysis in quantitative/statistic form with the purpose is to test the hypothesis that is stated" [6].

\section{Intervention procedure}

The athletes are divided into two groups: the experimental group $(\mathrm{N}=12)$ who follow the "elementary" training method and the control group program $(\mathrm{N}=12)$ who follow the game modification exercise method. Procedure of the research take place on the PEMDA of Mandailing Natal football field, (namely, 2 hours a week), with duration is 3 weeks.

\section{Observer reliability}

Video recording and trial retention of all participants are evaluated individually by two observers (soccer coach). Observers are not involved in any way in testing the conditions of the experiment. Each participant is only identified by their number. Each observer records the time and judged the athlete's skills on a standard score sheet that reflects the four elements of basic football technical skills. Observers are trained using video and stock watchfor

\section{RESULT}

The main effects in this study are (1) The difference of basic technical skills inplaying football of SSB Madina athletes who usethe elementary method group is more effective than the group that using game modifications, (2) The difference of the nutritional status group in the high category is better than in the nutritional status group low category of basic technical skills in playing football of SSB Madina athletes (3) There is an interaction between training method and nutritional status of basic technical skills in playing football. For more details, it can be seen in table 1.1

Table1. Summary of ANAVA Results of Two Paths toward Data on Basic Technique skills result in Playing Football Tests Between-Subjects Effects

\begin{tabular}{|c|c|c|c|c|}
\hline Variance & JK & Fh & pi & a \\
\hline \multirow{2}{*}{ Groups } & 1014.00 & \multirow{2}{*}{8023} &. & \multirow{2}{*}{0.05} \\
\cline { 2 - 5 } & 0 & & 010 & \\
\hline
\end{tabular}

\begin{tabular}{|c|c|l|l|l|}
\hline Interaction & 2128.16 & \multirow{2}{*}{16839} &. & \multirow{2}{*}{0.05} \\
\hline A X B & 7 & & 001 & \\
\hline \multirow{2}{*}{ Total } & 24262.5 & & & \\
\cline { 2 - 5 } & 00 & & & \\
\hline
\end{tabular}

Description:

JK = Number of Squares

\begin{tabular}{|c|c|c|}
\hline $\begin{array}{l}\text { example to ensure the } \\
\text { reliability of assessors and } \\
\text { one }\end{array}$ & $\mathrm{Fh}$ & $\begin{array}{l}=\text { Price F } \\
\text { arithmetic }\end{array}$ \\
\hline $\begin{array}{l}\text { scoring sheet per trial for } \\
\text { each athlete. The reliability } \\
\text { of the }\end{array}$ & $\mathrm{a}$ & $\begin{array}{l}=\text { Error } \\
\text { Tolerance }\end{array}$ \\
\hline $\begin{array}{l}\text { observer's senses is } \\
\text { examined after the } \\
\text { observation and } \\
\text { evaluation of } 12 \text { athletes } \\
\text { on the first day and the } \\
\text { evaluation }\end{array}$ & $\mathrm{p}^{*}$ & $\begin{array}{l}=\text { Probability } \\
=\text { Significant }\end{array}$ \\
\hline $\begin{array}{l}\text { of the same } 12 \text { athletes the } \\
\text { next day. }\end{array}$ & $* *$ & $\begin{array}{l}\text { = Very } \\
\text { Significant }\end{array}$ \\
\hline
\end{tabular}

\section{Instruments}

The equipments used for the implementation of the program are two cameras, tennis equipment (specifically a ball, cone, lines, and special field support), videos and personal computers for the evaluation of techniques used by athletes.

\section{Research design and statistical analysis}

The design used in this study is factorial in the form of $(2 \times 2)$. There is an independent variable "two groups" where the experimental group is an elementary training method and a game modification method and nutritional status control and "measurement" at one stage: posttest. The dependent variable is the basic technical skill of football.

One way Anova analysis is used to find out the interaction

effect. Statistical analysis of the data was made using the SPSS 17 program. Significance is determined at the 0.05 level. Before the data is analyzed the data is tested for variance, namely the Kolmogorov-Smirnov test (KS test) on the normality test of the variables and the covariance matrix equality test. There is a nonsignificant value ( $\mathrm{p}<0.05)$, which indicates that the data do not differ significantly from the multivariate normality of variables so that parametric tests can be applied.

Testing the second hypothesis is done using the Variance test (ANOVA) to see homogeneity between the two training methods and both nutritional status with the experimental design (A1B1B2, A2B1B2). Based on ANAVA calculation results, the two paths above can be stated that:

1. The alternative hypothesis $\left(\mathrm{H}_{\mathrm{a}}\right)$ states that there are differences in the basic football technical skills of 
SSB Madina athletes who use the group of elementary training methods more effectively than the group that Using game modification, the calculation results show that a significance value of $0.000<0.05$ is obtained, then $\mathrm{Ha}$ is accepted and Ho is refused.

2. The alternative hypothesis $\left(\mathrm{H}_{\mathrm{a}}\right)$ states that there is a difference in the nutritional status group of the high category better than the low category nutritional status group of football basic skills of SSB Madina athletes, with the calculation results showing that a significance value of $0.01<0.05$ is obtained, then $\mathrm{Ha}$ is accepted and Ho is rejected.

3. The alternative hypothesis $\left(\mathrm{H}_{\mathrm{a}}\right)$ which states that there is an interaction between the training method and nutritional status of football's basic technical skills, with the calculation results shows that a significance value of

$0.001<0.05$ is obtained, then Ha is accepted and

Ho is rejected.

By proving the research hypothesis, it states that there is an interaction between the elementary training method group and game modification group on the results of basic football skills in the SSB Madna athletes, the analysis needs to be followed by the Tuckey test. Based on the results of further tests using thetest, it can be stated that:

1. The fourth research hypotheses state that in the high category nutritional status group, by using the elementary training method (A1B1) is more effective than the game modification method (A2B1) is acceptable. The difference in interaction between (A1B1) and (A2B1) is stated as significant, as evidenced by sig. $0,000<0.05$.

2. The fifth research hypothesis states that in the low category nutritional status group, using the elementary training method (A1B2) is more effective than the game modification method (A2B2) can be accepted. The difference in interaction between (A1B2) and (A2B2) is stated as significant, as evidenced by sig. $0,000<0.05$.

\section{IV.DISCUSSION}

After analyzing the data using the two-way ANAVA approach and proceeding with thetest of the five proposed research hypotheses, all hypotheses are accepted. The research findings that conducted to SSB Madina athletes, the findings are presented in the previous section. This is due to the fact that to get the results of the basic technical skills of football the training methods used are seen and it is also necessary to look at the differences in the nutritional status of the athlete itself.

The acquisition of soccer skills is a fundamental thing for a game to have and is very important for achieving that skill. "Players spend most of their time in training with the aim of improving technical skills"[7].
In this study, the results of testing thefirsthypothesis shows that the overall score of the group training method given the elementary method was higher than that of the game modification group. In other words, the proposed research hypothesis is accepted. From these findings it can be argued that the elementary method group is more effectively used than the game modification group method. This can be seen from the results of statistical analysis with a difference of mean 56, this means that training using the elementary method group provides a better influence than the game modification method group.

Based on the above, the difference between the two training methods will give different results and it turns out that the provision of training methods with the form of elementary method can bring a better influence than the game modification method in term of the basic technical

skills of SSB Madina

athletes.

The result which is related to testing thesecondhypothesis shows that overall, high nutritional status scores are greater than low nutritional status scores. In other words, the hypothesis in research thisis accepted. Based on the results of the data, athletes who have a high level of nutritional status with the difference in means 267, preferably in the basic techniques skills of the athletes who have low levels of nutritional status group with the acquisition of mean 254the difference in means 13. This is caused the athletes who have group status High nutrition can keep your passion and desires better in following exercise. Like his desire in achieving a maximum result in participating in training and in following the match.

Conversely,the athletes with low nutritional status groups cannot easily absorb other forms of exercise during the training process. This is due to the emergence of a sense of boredom and frustration when training takes place, because there is a time to wait for their turn to use the ball, weather conditions, field infrastructure, training material provided is too heavy and so on so that what is desired and must be mastered in training is not achieved. Those athletes who have a high level of nutritional status are better at improving basic football skills than those who have a low nutritional status in SSB Madina.

The results that is related to thethirdhypothesis testing, namely interaction, it proves that there is an interaction between the training method and nutritional status in its effect on the basic technical skills of SSB Madina athletes or in other words, that the hypothesis being put to the test is true. The interaction between the training method and the athlete's nutritional status as described above can be illustrated through a comparison of the average scores of football basic technical skills between high and low categories of athletes with different treatments. The result shows that at the high nutritional status level, elementary training method are more effective than game modification training method on football playing skills, and vice versa. 
The results of thefourthhypothesis testing shows that in overall, the score of the training method given, the training of the elementary method is higher than the game modification exercise method at a high level of nutritional status. In other words, the proposed research hypothesis is accepted. From these findings it can be stated that the group of elementary training methods is more effectively used for the training method than the game modification group at high nutritional status in improving football playing skills.

The results of the fifth hypotheses testing show that in overall, the score of group training methods that are given the training method in the form of elementary training methods is more effective than those game modification methodat low nutritional status level. In other words, the proposed research hypothesis is accepted. Based on these findings, it can be stated that the elementary method group is more effectively used for the training method than the game modification exercise method at a low nutritional status level.

\section{CONCLUSION}

Based on the research findings and discussion of the results of the study, it can be concluded that the group of elementary training method is more effective than the game modification training group in influencing the basic technical skills of SSB Madina athletes, the high nutritional status group is more effective than the low nutritional status group in influencing the basic technical skills of SSB Madina athletes. There is an interaction between the training method and nutritional status on the basic technical skills of SSB Madina athletes. In the high nutritional status group, the elementary training method group is more effective than the game modification training group on the basic technical skills of Madina SSB athletes and in the low nutritional status group, the elementary training method group is more effective than the game modification exercise group on the basic technique skills of SSB Madina athletes.

\section{REFERENCES}

[1] Kirkendall, D.R., Gruber, J.J., \& Johnson, R.E., "Measure-ment and Evaluation for Physical Educators," Champaign, IL; Human Kinetics, 1987, pp. 34

[2] Ericsson, K. A., KRAMPE, R. T. and TESCH-ROMER, C, "The role of deliberate practice in the acquisition of expert performance," Psychological Review; 100, 1992, pp. 63 406.

[3] Koger, Robert, "Latihan Dasar Andal Sepakbola Remaja,"USA; The United States copyright. 2005, pp. 65.

[4] Thomas, C., Fellingham, G., \& Vehrs, P, "Development of a Notational Analysis System for Selected Soccer Skills of a Women's College Team," Measurement in Physical Education and Exercise Science; 13(2), 2007, pp, 108-121.

[5] Ali, A., Williams, C., Nicholas, C. W., \& Foskett, A, "The Influence of carbohydrate-electrolyte ingestion on soccer skill performance," Medicine and Science in Sports and Exercise, 2007, pp, 1969-1976.

[6] M. N. A. Setiawan. "Increasing Aerobic Durability Skill by Practicing Extensive Interval Method for Volleyball Athlete in
Rokan Hulu Regency", Applied Science and Technology, vol. 2, no. 1, pp. 129-131, February. 2018.

[7] Williams, A. M., \& Hodges, N. J, "Practice, instruction and skill acquisition in soccer; Challenging tradition," J. of Sports Sciences, Vol. 23, No. 6. 2005. pp, 637-650. 